\title{
CONCEPÇÕES DE ENFERMEIROS QUE ATUAM EM UNIDADE DE TERAPIA INTENSIVA GERAL SOBRE SEPSE*
}

José Melquiades Ramalho Neto, Daniela Alves Campos², Lailma Bento de Araújo Marques³, Carla Regina de Oliveira Couras Ramalho ${ }^{4}$, Maria Miriam Lima da Nóbrega ${ }^{5}$

${ }^{1}$ Enfermeiro. Mestre e Doutorando em Enfermagem. Universidade Federal da Paraíba. João Pessoa, PB, Brasil.

${ }^{2}$ Enfermeira. Faculdade de Enfermagem Nova Esperança. João Pessoa, PB, Brasil.

${ }^{3}$ Enfermeira. Especialista Residente Multiprofissional com Ênfase na Atenção ao Paciente Crítico. Universidade Federal da Paraíba. João Pessoa, PB, Brasil.

${ }^{4}$ Médica. Hospital Maria Alice Fernandes, Natal, RN, Brasil.

${ }^{5}$ Enfermeira. Doutora em Enfermagem. Docente do Departamento de Enfermagem da Universidade Federal da Paraíba. João Pessoa, PB, Brasil.

RESUMO: Pesquisa exploratória que visou verificar o entendimento de seis enfermeiros de uma Unidade de Terapia Intensiva Geral em relação à sepse. Os dados foram coletados nos meses de abril e maio de 2012 com um formulário estruturado, sendo utilizada a técnica do Discurso do Sujeito Coletivo para a análise dos dados. Os resultados revelaram conhecimento dos enfermeiros para o entendimento da sepse e a identificação de manifestações clínicas a ela relacionadas na prática profissional, bem como as atitudes profissionais embasadas nesse conhecimento, fazendo emergir cuidados intensivos de enfermagem que se entrelaçam com os bundles da Campanha de Sobrevivência à Sepse. Ressalta-se a importância do enfermeiro no reconhecimento precoce dos diferentes espectros clínicos relativos à sepse, subsidiando, dessa maneira, uma definição rápida de planos terapêuticos e estratégias adequadas de monitorização e cuidado dos pacientes graves.

DESCRITORES: Enfermagem; Sepse; Unidades de terapia intensiva; Cuidados críticos; Assistência centrada no paciente.

\section{CONCEPTIONS OF NURSES WHO WORK IN A GENERAL INTENSIVE CARE UNIT REGARDING SEPSIS}

ABSTRACT: This exploratory study aimed to ascertain the understanding of six nurses of a General Intensive Care Unit regarding sepsis. The data were collected in the months of April and May 2012 using a structured questionnaire, the Discourse of the Collective Subject technique being used for analyzing the data. The results revealed the nurses' knowledge regarding understanding of sepsis and the identification of clinical manifestations related to this in the professional practice, as well as the professional attitudes based in this knowledge, causing the emergence of intensive nursing care which is interlinked with the bundles of the Surviving Sepsis Campaign. The importance is emphasized of the nurse in the early recognition of the different clinical spectrums relating to sepsis - thus supporting a rapid definition of therapeutic plans and appropriate strategies for the monitoring and care of seriously ill patients.

DESCRIPTORS: Nursing; Sepsis; Intensive care units; Patientcentered care.

\section{CONCEPCIONES DE ENFERMEROS QUE ACTUAN EN UNIDAD DE TERAPIA INTENSIVA GENERAL ACERCA DE SEPSIS}

RESUMEN: Investigación exploratoria cuyo propósito fue verificar el entendimiento de seis enfermeros de una Unidad de Terapia Intensiva General acerca de sepsis. Los datos fueron obtenidos en los meses de abril y mayo de 2012 con un formulario estructurado, siendo utilizada la técnica del Discurso del Sujeto Colectivo para el análisis de los datos. Los resultados revelaron conocimiento de los enfermeros para el entendimiento de la sepsis y la identificación de manifestaciones clínicas a ella relacionadas en la práctica profesional, así como las actitudes profesionales embasadas en ese conocimiento, haciendo emerger cuidados intensivos de enfermería que se entrelazan con los bundles de la Campaña de Supervivencia a la Sepsis. Se destaca la importancia del enfermero en el reconocimiento precoz de los distintos espectros clínicos referentes a la sepsis, subsidiando, de esa forma, una definición rápida de planes terapéuticos y estrategias adecuadas de monitorización y cuidado de los pacientes graves.

DESCRIPTORES: Enfermería; Sepsis; Unidades de Terapia Intensiva; Cuidados críticos; Asistencia centrada en paciente.

*Artigo extraído do Trabalho de Conclusão de Curso de Graduação, intitulado: “Concepções e atitudes de enfermeiros intensivistas referentes à sepse." Faculdade de Enfermagem Nova Esperança, 2012.

\section{Autor Correspondente:}

José Melquiades Ramalho Neto

Universidade Federal da Paraíba

R. Lauro Torres, 174 - 58042-030 - João Pessoa, PB, Brasil

E-mail: melquiadesramalho@gmail.com
Recebido: 30/06/2015

Finalizado: 22/10/2015 


\section{INTRODUÇÃO}

A sepse representa uma das maiores causas de hospitalização e mortalidade nas Unidades de Terapia Intensiva (UTI) de todo o mundo ${ }^{(1-2)}$, estando diretamente associada às respostas inflamatórias sistêmicas graves, secundárias à infecção e caracterizando, dessa maneira, uma síndrome clínica relacionada às múltiplas possibilidades de uma complexa interação entre o microrganismo infectante e a resposta imune, pró-inflamatória e pró-coagulante do hospedeiro $^{(3)}$.

Apesar da disponibilidade dos modernos recursos diagnósticos, do uso de antibióticos de largo espectro, da monitorização hemodinâmica à beira do leito, do controle metabólico intensivo e das novas abordagens terapêuticas, a sepse se manifesta em distintos espectros de gravidade com o decorrer do tempo (sepse, sepse grave, choque séptico e disfunção de múltiplos órgãos e sistemas) caso não seja prontamente diagnosticada e tratada, representando altos custos anuais em seu tratamento ${ }^{(4-6)}$.

No ambiente de cuidados intensivos, há um risco aumentado para desenvolvêla devido aos vários fatores relevantes para o seu desencadeamento, como as doenças predisponentes do paciente crítico e o grau de severidade; o tempo de internação prolongado e debilitante, principalmente nos pacientes idosos; a prevalência mais acentuada de resistência bacteriana; os diversos procedimentos invasivos, como a intubação endotraqueal e a necessidade de ventilação mecânica, os acessos intravasculares, a sondagem vesical e outras intervenções que ocasionam a quebra das barreiras naturais do organismo.

No cenário brasileiro, dados epidemiológicos sobre as características dos pacientes com sepse nas UTIs tiveram início com o Brazilian Sepsis Epidemiogical Study, que evidenciou importante incidência da doença e aumento progressivo da mortalidade segundo os seus estágios evolutivos, com taxas de 33,9\% em pacientes críticos com sepse; $46,9 \%$ naqueles com sepse grave e $52,2 \%$ nos portadores de choque séptico ${ }^{(7)}$. Posteriormente, um estudo multicêntrico envolvendo diferentes regiões brasileiras buscou compreender melhor a epidemiologia da sepse e evidenciou uma taxa de incidência de 16,7\% com mortalidade global de $46,6 \%$ e que, quando discriminada em sepse, sepse grave e choque séptico, esses subgrupos apresentaram taxas de mortalidade de 16,7\%, $34,4 \%$ e $65,3 \%$, respectivamente ${ }^{(8)}$.
Nesse contexto, entende-se que o tratamento ágil e adequado torna-se crucial para o sucesso na abordagem do paciente séptico, diminuindo assim a incidência de disfunções orgânicas, por meio do importante papel assistencial de cada profissional na busca contínua pela detecção precoce de pacientes hospitalizados na fase inicial da síndrome ${ }^{(4)}$. Entretanto, ao lidar diuturnamente com esses pacientes graves, cabe ao enfermeiro planejar, coordenar e implementar ações que promovam o reconhecimento precoce dos diferentes espectros clínicos relativos à sepse não só pelo diagnóstico, mas também para as definições rápidas de planos terapêuticos e estratégias de monitorização, melhorando, dessa maneira, o prognóstico dos pacientes.

O interesse pelo desenvolvimento deste estudo surgiu no intuito de destacar o importante papel do enfermeiro intensivista, que deve continuamente avaliar e identificar necessidades humanas básicas não satisfeitas à beira leito na UTI para nortear a prestação precoce dos cuidados de enfermagem aos pacientes sépticos, os quais ainda ocorrem de forma assistemática ${ }^{(9)}$ e refletem escassez de publicações nessa área do cuidado intensivo.

$\mathrm{Na}$ tentativa de contribuir para a reflexão da importância de assistência de enfermagem individualizada e sistemática aos pacientes sépticos, que favoreça a redução da sua mortalidade na UTI, este estudo estruturou-se com o objetivo de verificar o entendimento de enfermeiros de uma Unidade de Terapia Intensiva Geral em relação à sepse.

\section{MÉTODO}

Pesquisa exploratória, de natureza qualitativa, realizada com todos os enfermeiros que atuam em uma UTI Geral da rede pública estadual do município de João Pessoa, estado da Paraíba, os quais se constituíram em seis participantes identificados por meio da letra $\mathrm{E}$ (enfermeiro) que foi seguida do número sequencial de inclusão na pesquisa (E1, E2, E3, E4, E5 e E6).

A coleta de dados ocorreu nos meses de abril e maio de 2012, obedecendo ao critério de inclusão: atuar profissionalmente na área de cuidados intensivos por tempo igual ou superior a seis meses. De acordo com os preceitos éticos preconizados para pesquisas envolvendo seres humanos ${ }^{(10)}$, o projeto foi aprovado pelo Comitê de Ética em Pesquisa das Faculdades de Enfermagem e Medicina Nova Esperança mediante CAAE ${ }^{\circ}$ 01580412.5.00005179, recebendo parecer favorável 
conforme Protocolo n ${ }^{\circ}$ 13/2012.

Durante a pesquisa foi solicitada resposta às seguintes questões: Conforme seu entendimento descreva o que é sepse. A partir de sua vivência assistencial na UTI, quais as manifestações da síndrome séptica que você identifica nos pacientes criticamente enfermos? Considerando a sua experiência, descreva as intervenções de enfermagem que você realiza diante de um paciente com sepse.

O método de análise foi o Discurso do Sujeito Coletivo (DSC), procedimento metodológico que faz uso de estratégia discursiva para tornar mais clara uma dada representação social sobre um fenômeno específico ${ }^{(11)}$.

No intuito de promover a fala coletiva dos enfermeiros desse estudo foram adotadas três figuras metodológicas: Expressões-chave $(\mathrm{ECH})$; Ideias Centrais (IC) e, por fim, o Discurso do Sujeito Coletivo (DSC). As ECH compreendem trechos ou transcrições literais do discurso que revelam a essência do pensamento de cada indivíduo ou, mais precisamente, do conteúdo discursivo dos segmentos em que se divide o depoimento, as quais devem ser destacadas pelo pesquisador. As IC são nomes ou expressões linguísticas que revelam e descrevem de maneira sintética, precisa e fidedigna o sentido de cada um dos discursos analisados e de cada conjunto homogêneo de $\mathrm{ECH}$ que, por sua vez, darão origem ao $\mathrm{DSC}^{(11)}$.

Para elucidar as ideias centrais deste estudo, recorreu-se à construção de um mapa conceitual a fim de demonstrar as concepções e cuidados intensivos de enfermagem ao paciente séptico. Para tanto, utilizou-se o CMap Tools em sua versão 5.03, um software desenvolvido e distribuído gratuitamente pelo Institute for Human Machine Cognition da University of West Florida ${ }^{(12)}$, o qual permite ao usuário construir modelos de relação conceitual, representados por diagramas de significados e relações significativas entre conceitos, cujo intuito é demonstrar a organização do conhecimento.

\section{RESULTADOS}

No tocante aos seis enfermeiros participantes da pesquisa, a idade variou entre 20 e 40 anos, com predomínio do gênero feminino e tempo de atuação de um a dez anos. Ademais, dentre esses enfermeiros, cinco apresentavam um tempo de labor significativamente recente na área de cuidados intensivos, não mais que cinco anos, o que reflete a situação de apenas um enfermeiro ser detentor de uma especialidade relacionada à assistência ao paciente grave (Enfermagem em Urgência e Emergência).

$\mathrm{Na}$ análise dos depoimentos, foram utilizadas as figuras metodológicas de linguagem, sendo identificadas e sublinhadasasECH decadaquestão; identificadas e agrupadas as IC de mesmo sentido, sentido equivalente ou mesmo complementar para construir o DSC propriamente dito. Assim, os temas e as IC que emergiram dos depoimentos dos enfermeiros estão apresentados no Quadro 1. No intuito de demonstrar as concepções e cuidados intensivos de enfermagem ao paciente séptico foi desenvolvido um mapa conceitual, apresentado na Figura 1.

A partir do tema inicial e da questão norteadora "Conforme seu entendimento descreva o que é sepse", a IC1 permitiu a construção do DSC1:

A sepse é uma resposta inflamatória à infecção, causada por germes patogênicos e que compromete vários órgãos do corpo humano. (DSC1)

$\mathrm{Na}$ sequência da análise dos depoimentos desse mesmo tema à questão norteadora: "A partir de sua vivência assistencial na UTI, quais as manifestações da síndrome séptica que você identifica nos pacientes criticamente enfermos?", emergiu a IC2 que evidenciou a percepção dos enfermeiros no DSC2:

Hipotermia ou hipertermia, taquicardia, hipotensão, desconforto respiratório, taquipnéia, alteração do nível de consciência, oligúria aguda, edema, escaras de decúbito que só pioram e leucocitose. (DSC2)

Quadro 01 - Temas e ideias centrais. João Pessoa, PB, Brasil, 2012

\begin{tabular}{|l|l|}
\hline \multicolumn{1}{|c|}{ TEMAS } & \multicolumn{1}{|c|}{ IC } \\
\hline Conhecimentos requeridos na prática profissional & 1: Entendimento acerca da sepse \\
\cline { 2 - 3 } & $\begin{array}{l}\text { 2: Identificação de manifestações clínicas relacionadas } \\
\text { à sepse }\end{array}$ \\
\hline Atitudes assistenciais requeridas na prática profissional & $\begin{array}{l}\text { 3: Cuidados intensivos de enfermagem ao paciente } \\
\text { séptico }\end{array}$ \\
\hline
\end{tabular}




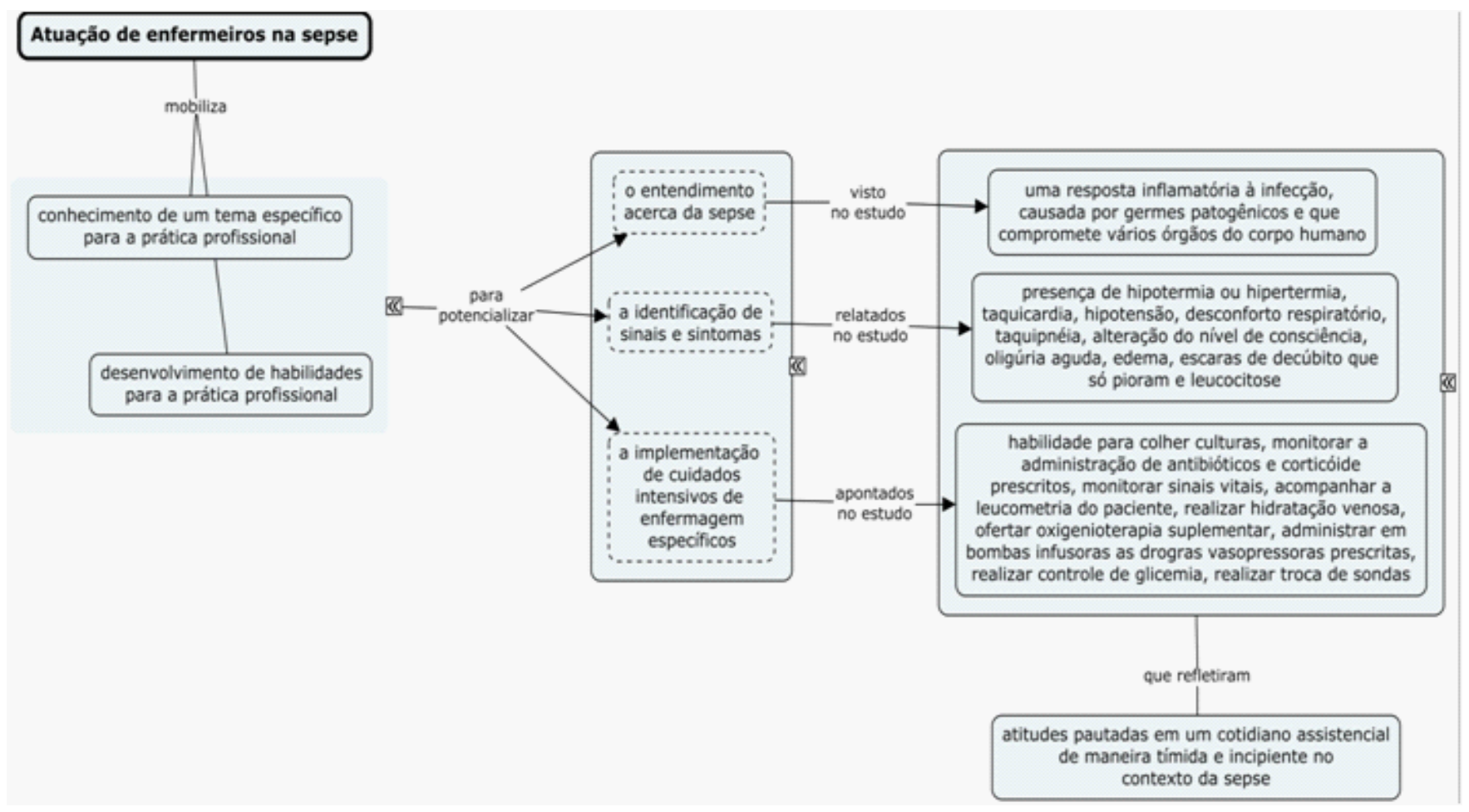

Figura 1 - Atuação de enfermeiros intensivistas na sepse. João Pessoa, 2012

Por fim, sobre as respostas dos enfermeiros intensivistas ao questionamento "Considerando a sua experiência, descreva as intervenções de enfermagem que você realiza diante de um paciente com sepse", a IC3 apontou para uma dimensão atitudinal evidenciada na construção do DSC3:

É necessário colher culturas, monitorar a administração de antibióticos e corticóide prescritos, monitorar sinais vitais, acompanhar a leucometria do paciente, realizar hidratação venosa, ofertar oxigenoterapia suplementar, administrar em bombas infusoras as drogas vasopressoras prescritas, realizar controle de glicemia, realizar troca de sondas. (DSC3)

\section{DISCUSSÃO}

Conforme evidenciado nos resultados, os enfermeiros entendem a sepse como uma síndrome complexa desenvolvida pelo ser humano em resposta à invasão de microrganismos patogênicos. Entretanto, diferentemente da concepção de infecção generalizada, encontrada em dois dos depoimentos, ela é verdadeiramente causada por uma resposta inflamatória sistêmica sem controle efetivo do organismo de um indivíduo, desencadeada por infecção bacteriana, viral, fúngica ou parasitária, caracterizada por manifestações múltiplas e que pode determinar disfunção ou falência de um ou mais órgãos, ou mesmo a morte ${ }^{(2,13)}$.

Embora o comprometimento da relação entre oferta e consumo de oxigênio seja um dos principais mecanismos de disfunção na sepse ${ }^{(14)}$, essa entidade clínica não se limita apenas ao local inicial da infecção. Sua evolução varia de acordo com o tempo de diagnóstico e a debilidade do estado de saúde do paciente, o qual pode desenvolver disfunção orgânica nos diferentes sistemas corporais, como o cardiovascular, respiratório, neurológico, renal, digestivo, hematológico e endócrino. Além disso, não existe progressão linear de todas as fases da síndrome séptica (sepse, sepse grave, choque séptico e disfunção de múltiplos órgãos e sistemas), tendo em vista que na prática cotidiana da UTI podese observar a instalação rápida e progressiva do quadro de choque séptico sem a identificação anterior dos sinais de sepse.

Nesse contexto, pode ainda haver diagnósticos tardios devido à não suspeita de sepse, e os sintomas clínicos e sinais laboratoriais, atualmente utilizados para o diagnóstico, como febre, taquicardia, taquipnéia ou alterações na contagem de leucócitos não serem específicos da sepse $^{(15)}$.

A habilidade que emerge na IC2 acerca da prática profissional de Enfermagem em reconhecer efetivamente manifestações clínicas de sepse nos pacientes graves, e sabidamente 
entender que a existência de possíveis focos de infecção, como úlceras por pressão, pode influenciar positivamente no desencadeamento da mesma, podem decorrer de uma experiência pautada no cotidiano assistencial desses enfermeiros de modo principiante e tímido.

Nesse sentido, vale ressaltar que a identificação precoce de sinais de sepse pelo enfermeiro constitui fator impactante na redução de mortalidade, muito embora as diretrizes da Campanha de Sobrevivência à Sepse ${ }^{(16)}$ tenham primado por uma abrangente revisão das condutas direcionadas aos pacientes sépticos e sutilmente silenciado os cuidados de enfermagem, extremamente essenciais para o prognóstico final desses pacientes ${ }^{(17)}$.

Mesmo assim, alterações agudas causadas pela incipiente ou atual infecção podem ser monitoradas pela avaliação de potenciais alterações em variáveis clínicas gerais, como febre ou hipotermia, frequência cardíaca $>90$ batimentos/minuto, taquipnéia, estado mental alterado, edema significativo ou balanço hídrico positivo e hiperglicemia na ausência de diabetes; em variáveis inflamatórias, como leucocitose ou leucopenia, presença $>10 \%$ de neutrófilos imaturos, elevação dos níveis de proteína C-reativa e/ou de procalcitonina; em variáveis hemodinâmicas, como hipotensão arterial, saturação venosa central $>70 \%$ e índice cardíaco $>3,5 \mathrm{~L} / \mathrm{min} / \mathrm{m} 2$; em variáveis de disfunções orgânicas, como hipoxemia arterial, débito urinário $<0,5 \mathrm{~mL} / \mathrm{kg} /$ hora por pelo menos duas horas, aumento da creatinina, alterações de coagulação, ausência de ruídos hidroaéreos, plaquetopenia ou hiperbilirrubinemia; e, por fim, em variáveis de perfusão tecidual, como hiperlactatemia e tempo de enchimento capilar lentificado ou livedo reticular ${ }^{(16-17)}$.

No tocante ao campo atitudinal reportado na IC3, percebe-se que as atitudes dos enfermeiros se entrelaçam com os bundles da Campanha de Sobrevivência à Sepse ${ }^{(16)}$, que preconiza nas primeiras 3 horas medir o nível de lactato, colher hemoculturas antes da administração de antibióticos, implementar antibioticoterapia precoce e de largo espectro, e administrar fluidos cristaloides naqueles pacientes com hipotensão arterial ou lactato $\geq 4 \mathrm{mmol} / \mathrm{L}$. Após essa primeira fase e até a sexta hora, verifica-se a necessidade de outras intervenções de acordo com a evolução clínica dos pacientes sépticos, com uso de vasopressores para manter uma pressão arterial média $\geq 65 \mathrm{mmHg}$ diante de hipotensões refratárias à ressuscitação hídrica inicial; a mensuração de pressão venosa central e de saturação venosa central de oxigênio.

A sepse na sua amplitude merece visão detalhada por parte da equipe multiprofissional, principalmente do enfermeiro que está mais próximo do paciente diuturnamente, tendo em vista que os processos complexos a ele inerentes contribuem decisivamente para a mortalidade dos pacientes graves e resultam em elevado impacto econômico e social. Assim, a adoção de estratégias voltadas para a identificação precoce de pacientes com risco de sepse, melhora as chances de sobrevivência e impede a evolução da síndrome para estágios mais graves, como o choque séptico.

\section{CONCLUSÃO}

Segundo análise dos discursos, entende-se que os objetivos foram alcançados, pois revelaram o entendimento e as condutas realizadas pelos enfermeiros em relação à síndrome séptica condizentes com os bundles enfatizados pela Campanha de Sobrevivência à Sepse, protocolos que visam facilitar e auxiliar o trabalho daqueles profissionais que estão à beira-leito.

Assim sendo, a tarefa de cuidar do paciente gravemente enfermo na UTI exige conhecimento de enfermagem especializado, devido às diferentes e complexas demandas de atenção, necessárias para identificar tanto os sinais de sepse quanto os potenciais indícios de deterioração clínica do paciente séptico.

Levando-se em consideração que a terapia intensiva vem absorvendo mudanças importantes ao longo das últimas décadas, percebe-se a importância do enfermeiro no reconhecimento precoce dos diferentes espectros clínicos relativos à sepse não só pelo diagnóstico, mas sim para que ele possa traçar definições rápidas dos planos terapêuticos de enfermagem e das estratégias adequadas de monitorização frente a essa situação crítica tão complexa e de manifestações tão amplas.

\section{REFERÊNCIAS}

1. Kleinpell R, Aitken L, Schorr CA. Implications of the new international sepsis guidelines for nursing care. Am J Crit Care. [Internet] 2013; 22(3) [acesso em 02 jun 2015]. Disponível: http://dx.doi.org/10.4037/ ajcc2013158.

2. Siqueira BF, Rosanelli CS, Stumm EMF, Loro 
MM, Piovesan SMS, Hildebrandt LM, et al. Nurses' conceptions regards to sepsis in patients in intensive care. J. Nurs. UFPE on line. [Internet] 2011; 5(1) [acesso em 02 jun 2015]. Disponível: http://www.revista.ufpe. $\mathrm{br} / \mathrm{revistaenfermagem/index.php/revista/article/}$ view/1479.

3. Gauer RL. Early recognition and management of sepsis in adults: the first six hours. Am Fam Physician. [Internet] 2013; 88(1) [acesso em 13 ago 2015]. Disponível: http://www.aafp.org/afp/2013/0701/p44. html.

4. Westphal GA, Feijó J, Andrade PS, Trindade L, Suchard C, Monteiro MAG, et al. Estratégia de detecção precoce e redução de mortalidade na sepse grave. Rev. bras. ter. intensiva. 2009; 21(2):113-23.

5. Picard KM, O'Donoghue SC, Young-Kershaw DA, Russell KJ. Development and implementation of a multidisciplinary sepsis protocol. Crit. care nurse. [Internet] 2006; 26(3) [acesso em 18 mai 2015]. Disponível: http://ccn.aacnjournals.org/ content/26/3/43.full.pdf+html.

6. Siqueira-Batista R, Gomes AP, Calixto-Lima L, Vitorino RR, Perez MCA, Mendonça EG, et al. Sepse: atualidades e perspectivas. Rev. bras. ter. intensiva. 2011; 23(2):207-16.

7. Silva E, Pedro MA, Sogayar AC, Mohovic T, Silva CL, Janiszewski M, et al. Brazilian Sepsis Epidemiological Study (BASES study). Crit Care [Internet]. 2004; 8(4) [acesso em 18 mai 2015]. Disponível: http://dx.doi. org/10.1186/cc2892.

8. Sales Júnior JAL, David CM, Hatum R, Souza PCSP, Japiassú A, Pinheiro CTS, et al. Sepse Brasil: estudo epidemiológico da sepse em unidades de terapia intensiva brasileiras. Rev. bras. ter. intensiva. 2006;18(1):09-17.

9. Ramalho Neto JM, Fontes WD, Nóbrega MML. Instrumento de coleta de dados de enfermagem em Unidade de Terapia Intensiva Geral. Rev. bras. enferm. 2013; 66(4):535-42.

10. Ministério da Saúde (BR). Conselho Nacional de Saúde. Aprova diretrizes e normas regulamentadoras de pesquisas envolvendo seres humanos. Resolução n. 196, de 10 de outubro de 1996. Brasília; 1996.

11. Lefèvre $F$, Lefèvre AMC. O discurso do sujeito coletivo: um novo enfoque em pesquisa qualitativa (desdobramentos). $2^{\text {a }}$ ed. Caxias do Sul: EDUCS; 2005.

12. Institute for Human and Machine Cognition - Cmap Tools [Internet]. Florida: University of West Florida; 2014 [acesso em 25 jun 2015]. Disponível: http://cmap. ihmc.us/cmaptools/.

13. Valerio TA, Cancelier AC, Constantino L, Petronilho
F, Ritter C, Dal-Pizzol F. Marcadores inflamatórios e oxidativos em sangue de cordão umbilical como preditores de gravidade em sepse neonatal. Rev. bras. ter. intensiva. 2012; 24(1):30-4.

14. Westphal GA, Gonçalves AR, Caldeira Filho M, Silva E, Salomão R, Bernardo WM, et al. Diretrizes para tratamento da sepse grave/choque séptico - avaliação da perfusão tecidual. Rev. bras. ter. intensiva. 2011; 23(1):6-12.

15. Reinhart K, Daniels R, Machado FR. O ônus da sepse: uma chamada em apoio ao Dia Mundial da Sepse 2013. Rev. bras. ter. intensiva. 2013; 25(1):3-5.

16. Dellinger RP, Levy MM, Rhodes A, Annane D, Gerlach H, Opal SM, et al. Surviving sepsis campaign: international guidelines for management of severe sepsis and septic shock, 2012. Intensive Care Med. [Internet] 2013; 39(2) [acesso em 14 jun 2015]. Disponível: http://health.springer.com/article/10.1007/ s00134-012-2769-8/fulltext.html.

17. Aitken LM, Williams $G$, Harvey $M$, Blot $S$, Kleinpell R, Labeau $S$, et al. Nursing considerations to complement the Surviving Sepsis Campaign guidelines. Crit Care Med. [Internet] 2011; 39(7) [acesso em 13 ago 2015]. Disponível: https://dx.doi.org/10.1097/ CCM.0b013e31821867cc. 